\title{
A New Method for Weld Dilution Calculation through Chemical Composition Analysis
}

\author{
Zhanhui Zhang ${ }^{1,2, *} \mathbb{C}$, Xuefei Huang ${ }^{1, *}$, Ping Yao ${ }^{3}$ and Jiaxiang Xue ${ }^{4}$ \\ 1 Guangzhou Panyu Polytechnic, Guangzhou 511483, China \\ 2 China-Ukraine Institute of Welding, Guangdong Academy of Sciences, Guangzhou 510650, China \\ 3 College of Electromechanical Engineering, Guangdong Polytechnic Normal University, \\ Guangzhou 510635, China; ypsunny@163.com \\ 4 School of Mechanical and Automotive Engineering, South China University of Technology, \\ Guangzhou 510641, China; mejiaxue@scut.edu.cn \\ * Correspondence: mezhangzh@mail.scut.edu.cn (Z.Z.); huangxf@gzpyp.edu.cn (X.H.); \\ Tel.: +86-17728101097 (Z.Z.); +86-13610304840 (X.H.)
}

check for updates

Citation: Zhang, Z.; Huang, X.; Yao, P.; Xue, J. A New Method for Weld Dilution Calculation through Chemical Composition Analysis. Metals 2021, 11, 131.

https: / / doi.org/

10.3390/met11010131

Received: 13 December 2020

Accepted: 8 January 2021

Published: 11 January 2021

Publisher's Note: MDPI stays neutral with regard to jurisdictional clai$\mathrm{ms}$ in published maps and institutional affiliations.

Copyright: (C) 2021 by the authors. Licensee MDPI, Basel, Switzerland. This article is an open access article distributed under the terms and conditions of the Creative Commons Attribution (CC BY) license (https:// creativecommons.org/licenses/by/ $4.0 /)$.

\begin{abstract}
Aiming at existing methods unable to reveal the definition of dilution in welding accurately, such as the limited formula's range of $0 \sim 1$ mathematically, a new way which can be widely applied to various welds alloying either one or more compositions was proposed. Dilution values obtained using different methods through chemical composition analysis were compared and the effect of heat inputs on dilution was researched. The results show that the proposed method fabricated mathematically agrees well with the definition of dilution in welding. Especially, by dilution increasing to a level higher than the critical value, it reveals the fact that a weld can be concentrated as well when the filler wire is rich in the same composition as the substrate does. Besides, the method demonstrates that the gross dilution for a bead is a combined result that is affected by each individual composition. However, whether a composition is diluted or concentrated, composition's concentrations are propelled by the increase of heat input toward that of the original substrate. During the process, the dilution value changes sharply before the heat input reaches the transition point (TP) of $0.18 \mathrm{~kJ} / \mathrm{mm}$, while once the heat input is beyond TP, the dilution becomes stable.
\end{abstract}

Keywords: dilution; gas metal arc welding; chemical composition; aluminum alloys; concentration

\section{Introduction}

Dilution is a significant factor affecting the mechanical property of bead in gas metal arc welding (GMAW) [1-5]. For example, the microhardness increases with the aluminium ratio in the steel-on-aluminium weld [1,2], and the welded joint with a lower dilution ratio of copper in the fusion zone exhibits higher tensile strength [3]. Besides, several researchers [6,7] found that microhardness is very sensitive to the change of dilution ratio in spot welding of steel, and a small change of dilution ratio will cause significant microhardness difference. The experimental investigation of residual stresses in multipass steel welds indicates that dilution significantly affects the stress state of the welds, and higher dilution reduces tensile stress or promotes compressive stress in the as-deposited and reheated weld metals [8,9]. Moreover, it is also found that for the weld joint with a lower dilution ratio, no cracking phenomenon is observed during a bending test. For the weld joint with a higher dilution ratio, cracking phenomenon initiated at the $309 \mathrm{~L}$ cladding layer is present, and a significant reduction from $634 \mathrm{MPa}$ to $521 \mathrm{MPa}$ in tensile test is observed [10]. There are mainly two ways to calculate the dilution of weld bead: chemical analysis and geometric calculations [11-16]. Considering that the dilution values obtained from the two techniques are quite close [11], most researchers adopted the geometric calculations method to calculate the dilution in various processes owing to its simplicity and efficiency compared with the chemical analysis $[12,14,17,18]$. These two methods, 
however, cannot reflect the definition of dilution in welding well and accurately. Dilution is defined as the level at which the composition(s) in substrate mixes with that in the filler wire [17]. Although in welding the substrate is undoubtedly diluted by the filler wire, the dilution ratio cannot be simply expressed as Equation (1) [12], which irrationally correlates the original concentration of the substrate and the filler wire just to make it easier for the dilution calculation. Moreover, it can be only employed to assess the weld alloying one element but not able to measure the gross dilution for a weld containing more compositions $[13,16]$, for which case its only value cannot be used to represent different dilution ratios.

$$
D=\frac{C_{w}-C_{f w}}{C_{s}-C_{f w}}
$$

where $D$ is the dilution level, and $C_{w}, C_{f w}, C_{s}$ are the elemental compositions of the fusion zone, filler wire, and substrate, respectively. Moreover, the geometric method expressed as Equation (2) [12,19] is more popular because of its simplicity in calculation, while this method is even further from the truth than Equation (1) owing to its lack of integrating the element composition into its formula. Furthermore, for a weld alloying more than one composition, it is hard for researchers to decide which composition dilution it reveals exactly.

$$
D=A_{p} /\left(A_{p}+A_{r}\right)
$$

where $A_{p}, A_{r}$ are the areas of weld penetration and reinforcement, respectively. The difference in the dilution value for different compositions is also displayed in References $[11,13]$ by Gualco and Silva, respectively. According to their study, the composition of $\mathrm{Cr}$ and $\mathrm{Nb}$ shows quite different dilution values as well.

Based on the above analysis of the used methods of dilution ratio, it can be found that the results of dilution ratio calculated by the existing two methods are quite different. Moreover, according to the definition of dilution ratio, it is a concept set up to investigate the change of composition concentration of a weld. Therefore, the calculation of the dilution ratio cannot be carried out simply by dividing the area of a weld into two parts and calculating their area ratio (namely, the geometric method), although the melting of base metal and the filler wire does change the profile of a weld bead. Therefore, the calculation of dilution ratio should be based on the analysis of chemical composition. Meanwhile, it should be recognized that the dilution ratio is different for various weld compositions in one bead. Thus, how to calculate the dilution ratio of all major alloying compositions and how to determine the relationship between the element dilution ratios need further study.

Hence, to calculate the dilution precisely and widely for various welds alloying one or more compositions, a new way is proposed, which is well fabricated mathematically and loyal to the dilution definition in welding. Besides, the effect of different heat inputs on dilution is researched as well using the new method.

\section{Materials and Methods}

A bead-on-plate welding experiment was conducted on aluminum alloy AA6061 base metal $(250 \mathrm{~mm} \times 60 \mathrm{~mm} \times 3 \mathrm{~mm})$ using ER4047 filler wire of $\varphi 1.2 \mathrm{~mm}$, and the experimental setup is displayed in Figure 1a. The welding process is automatized with a torch attached vertically to the fixture on the guide rail. The respective compositions of each material used in this study are provided in Table 1. Pulsed GMAW with good stability was employed to obtain different average current which changes within a wide range by adjusting the base current as displayed in Figure $1 b[20,21]$, and the collected signals show that there is no arc extinction and both the pulsed current and voltage have good repetitiveness (Figure 1c). The parameters for welding are presented in Table 2. Pure argon was coaxially supplied as a shielding gas at a flow rate of $18 \mathrm{~L} / \mathrm{min}$. The specimens were cut along the transverse cross-sections of the middle part of a weld, then ground and polished with colloidal silica and subsequently etched for $30 \mathrm{~s}$ using the standard Keller agent $\left(95 \mathrm{~mL} \mathrm{H}_{2} \mathrm{O}, 1 \mathrm{~mL} \mathrm{HCl}, 1.5 \mathrm{~mL} \mathrm{HF}\right.$, and $\left.2.5 \mathrm{~mL} \mathrm{HNO}_{3}\right)$. Chemical composition 
is tested using energy-dispersive X-ray spectroscopy (EDS) NOVA NANOSEM 430 (FEI, Hillsboro, OR, USA), and the EDS parameters used in our study are $15.3 \mathrm{keV}$ and $9.8 \mathrm{~mm}$. To improve the accuracy of dilution, three specimens were tested for each case.

(a)

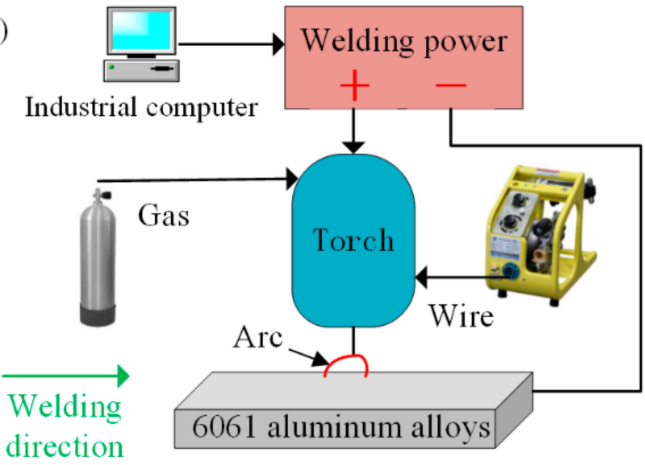

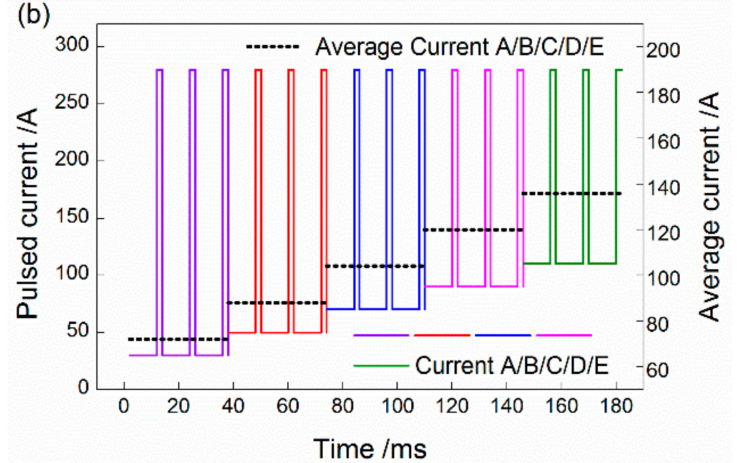

(c)

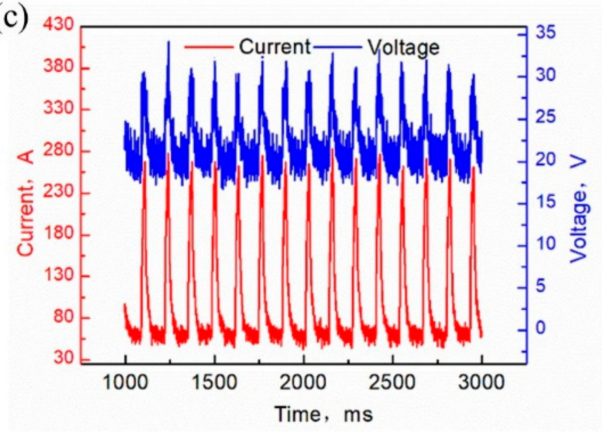

Figure 1. Schematic of (a) experimental setup, (b) the adjustment of average current, and (c) the collected signal of current and voltage.

Table 1. Chemical compositions of base metal AA6061 and filler wire ER4047 (wt \%).

\begin{tabular}{lcccccccc}
\hline Material & $\mathbf{M g}$ & $\mathbf{S i}$ & $\mathbf{F e}$ & $\mathbf{C u}$ & $\mathbf{M n}$ & $\mathbf{C r}$ & $\mathbf{T i}$ & Al \\
\hline AA6061 & 0.87 & 0.66 & 0.42 & 0.29 & 0.09 & 0.27 & 0.08 & Bal. \\
ER4047 & 0.05 & 11.06 & 0.30 & 0.13 & 0.12 & 0.04 & 0.07 & Bal. \\
\hline
\end{tabular}

Table 2. Welding process parameters for pulsed gas metal arc welding (P-GMAW).

\begin{tabular}{cc}
\hline Process Parameters & Value \\
\hline Mean voltage $(\mathrm{V})$ & 24.3 \\
Mean current $(\mathrm{A})$ & A:72 B:88 C:104 D:120 E:36 \\
Welding speed $(\mathrm{mm} / \mathrm{s})$ & 10 \\
Heat input $(\mathrm{kJ} / \mathrm{mm})$ & A:0.12 B:0.15 C:0.180.18 D:0.20 E:0.0.23
\end{tabular}

\section{Results and Discussion}

\subsection{Sampled Areas and Alloying Compositions}

Dilution is defined as the level at which the composition(s) in substrate mixes with that in the filler wire [17], therefore, it can be determined as a ratio of the compositions concentration in fusion zone to that in original substrate, which can be expressed mathematically as Equation (3). Owing to the dilution in the welding means the diluted extent of the substrate compositions; therefore, both the top/back reinforcement and the sunken area cannot be selected as sampled areas. Besides, the profile of weld beads changes significantly with heat input [22,23], the reason for which has been discussed in our previous work [24]. Hence, the sampled areas used for the element analysis and calculation for various weld 
profiles are displayed as the red region in Figure 2. Moreover, to avoid any deviations that may be encountered due to micro-segregation [12], the three sampled areas for each heat input were at least $10,000 \mu^{2}$.

$$
\mathrm{D}(\%)=C_{w} / C_{s}
$$
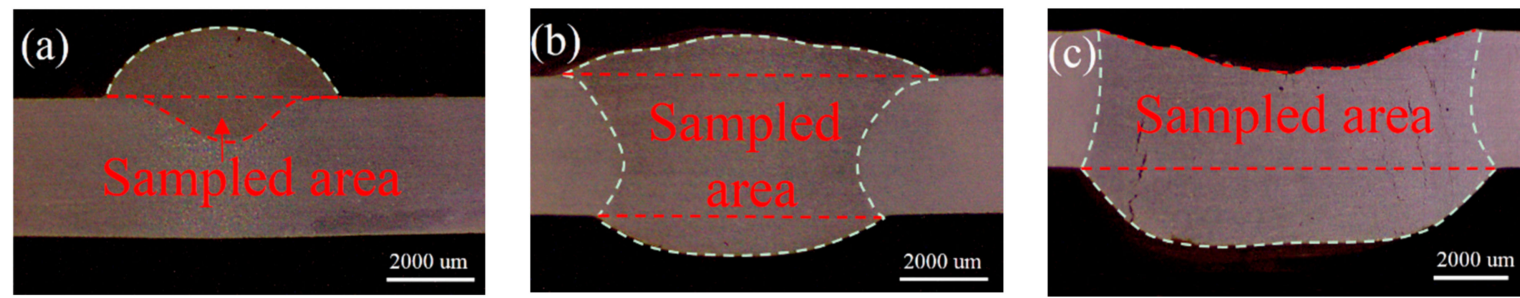

Figure 2. Sampled areas for various weld profiles. Heat input of (a) $0.12 \mathrm{~kJ} / \mathrm{mm}$; (b) $0.18 \mathrm{~kJ} / \mathrm{mm}$; (c) $0.23 \mathrm{~kJ} / \mathrm{mm}$.

In our study, $\mathrm{Mg}$ and $\mathrm{Si}$ are taken as the targeted compositions to analyze the dilution due to the fact that they are the main alloying elements for the substrate. According to Equation (3), the dilution for $\mathrm{Mg}$ and $\mathrm{Si}$ can be expressed as the ratio of their concentrations after welding (namely, the weld concentration) to that before welding (namely, the substrate concentration), respectively.

\subsection{Comparison of Dilutions from Different Equations}

Figure 3 represents the energy-dispersive X-ray spectroscopy (EDS) analyses of the substrate, filler wire, and the three various beads mentioned above. Table 3 lists the result of the main alloying compositions analysis of $\mathrm{Mg}$ and Si using EDS for different samples and heat inputs. Then, the dilution results calculated using Equations (1)-(3) are displayed in Figure 4 and Table 4 based on the EDS results. As we can see, the dilution ratios are quite different. All the results derived from Equations (1) and (2) fluctuates mathematically in the range of $0 \sim 1$ (the dashed lines in Figure 4), which is not consistent with the fact in welding that the weld is not always diluted at any case but can be concentrated as well in the cases when the filler wires are greatly rich in the same alloying elements as the substrate do. In these cases, due to the substantial addition of melted filler wire, the forced limited dilution range derived from the existing mathematical formula loses the ability to indicate the real condition that happened in welding. The reason for the limited dilution range gained from Equation (2) is obvious, because $A_{p}$ will never be greater than the sum of $A_{p}+A_{r}$, while it is a little complicated for Equation (1). As is known, a certain element concentration always fluctuates between that of the filler wire and the substrate, which means either $C_{f w N} \leq C_{w N} \leq C_{s N}$ or $C_{s N} \leq C_{w N} \leq C_{f w N}$, where $C_{s N}, C_{w N}$ and $C_{f w N}$ are concentrations of a certain element in substrate, weld, and filler wire. Nevertheless, whichever case the situation is, the absolute difference value of $C_{w N}-C_{f w N}$ will never exceed that of $C_{s N}-C_{f w N}$, which means that the dilution result obtained according to Equation (1) will be neither greater than 1, nor less than 0 . Therefore, owing to the irrational restriction mathematically on the dilution range imposed by Equations (1) and (2), neither is a rational method to illustrate the definition of dilution in welding, despite their simplicity in the calculation.

The difference of the dilution value for different compositions by existing methods also found in References [11,13] by Gualco and Silva, respectively, as we can see from Table 5, the value varies from geometric dilution to Chemical analysis. Moreover, even for the Chemical analysis, the dilution values also display an evident difference for different heat inputs, such as the different values between the element $\mathrm{Cr}$ to the element $\mathrm{Nb}$. 

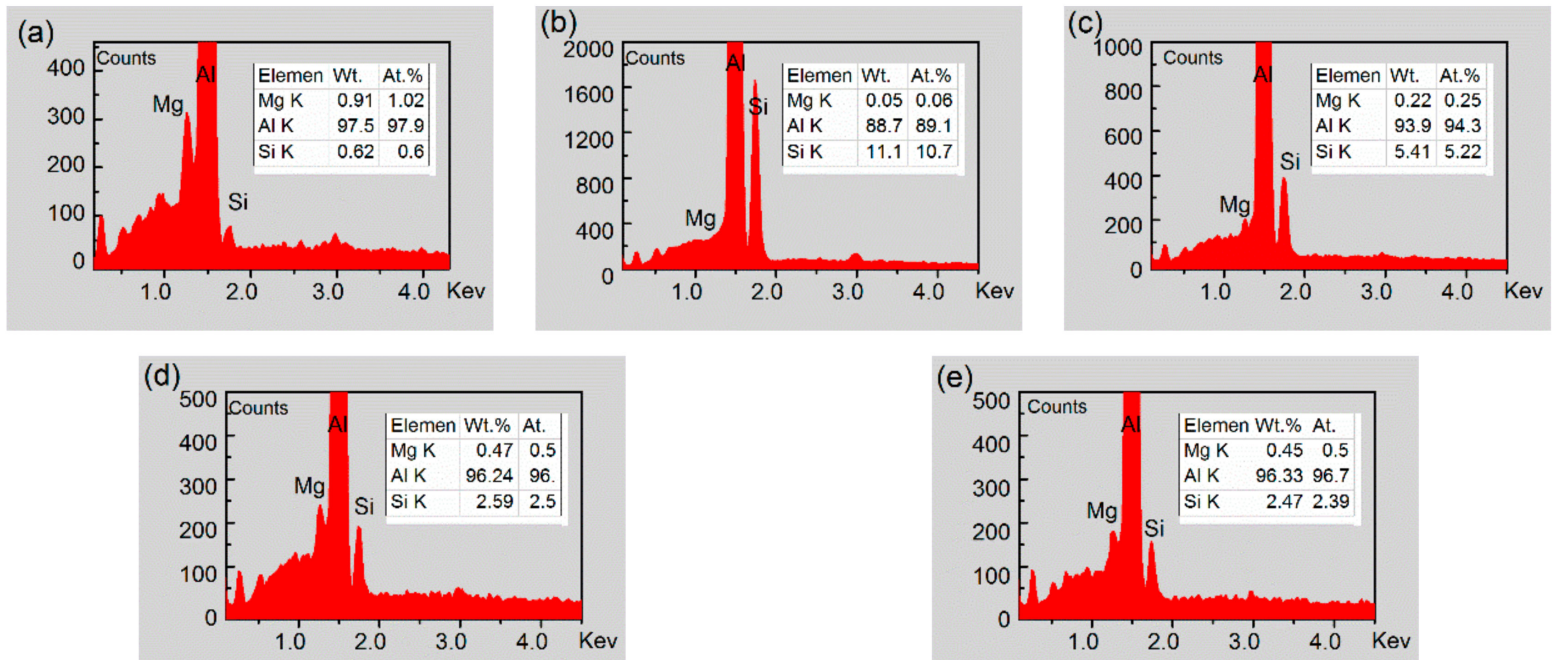

Figure 3. EDS analyses of (a) substrate, (b) filler wire and the three various beads: heat input of (c) $0.12 \mathrm{~kJ} / \mathrm{mm}$; (d) $0.18 \mathrm{~kJ} / \mathrm{mm} ;(\mathbf{e}) 0.23 \mathrm{~kJ} / \mathrm{mm}$.

Table 3. Concentration of $\mathrm{Mg}$ and $\mathrm{Si}$ in different beads (wt\%).

\begin{tabular}{cccccc}
\hline Heat Input $\mathbf{( k J / m m )}$ & $\mathbf{0 . 1 2}$ & $\mathbf{0 . 1 5}$ & $\mathbf{0 . 1 8}$ & $\mathbf{0 . 2 0}$ & $\mathbf{0 . 2 3}$ \\
\hline $\mathrm{Mg}$ & 0.24 & 0.42 & 0.42 & 0.46 & 0.43 \\
$\mathrm{Si}$ & 5.87 & 3.87 & 2.43 & 2.62 & 2.65 \\
\hline
\end{tabular}

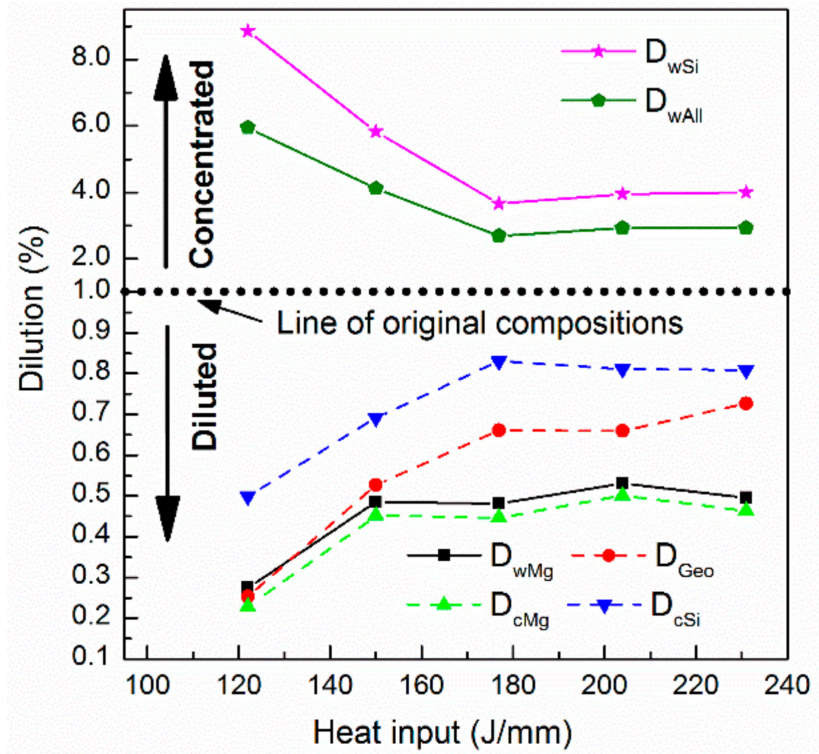

Figure 4. Comparison of dilutions calculated using three different methods.

Table 4. Comparison of dilutions calculated using three different methods.

\begin{tabular}{ccccccc}
\hline Heat Input kJ/mm & $\mathbf{D}_{\text {geo }}$ & $\mathbf{D}_{\mathbf{c M g}}$ & $\mathbf{D}_{\mathbf{c S i}}$ & $\mathbf{D}_{\mathbf{w M g}}$ & $\mathbf{D}_{\text {wSi }}$ & $\mathbf{D}_{\text {wAll }}$ \\
\hline 0.12 & 0.25 & 0.23 & 0.5 & 0.27 & 8.85 & 5.94 \\
0.15 & 0.53 & 0.45 & 0.69 & 0.48 & 5.83 & 4.11 \\
0.18 & 0.66 & 0.45 & 0.83 & 0.48 & 3.66 & 2.69 \\
0.20 & 0.66 & 0.5 & 0.81 & 0.53 & 3.95 & 2.92 \\
0.23 & 0.73 & 0.46 & 0.81 & 0.5 & 4 & 2.93 \\
\hline
\end{tabular}


Table 5. Data of dilution determined by both geometric measurements and chemical analysis.

\begin{tabular}{ccccccc}
\hline Heat Input, $\mathbf{k J} / \mathbf{m m}$ & $\mathbf{0 . 5}$ & $\mathbf{0 . 7}$ & $\mathbf{1}$ & $\mathbf{1 . 5}$ & $\mathbf{1 . 7}$ & $\mathbf{2 . 1}$ \\
\hline Geometric Dilution & 30 & 32 & 34 & 36 & 35 & 36 \\
Chemical Analysis of Cr & 31.93 & 33.13 & 36.14 & 37.35 & 36.75 & 38.55 \\
Chemical Analysis of Nb & 16.09 & 22.99 & 25.29 & 25.29 & 27.59 & 25.29 \\
\hline
\end{tabular}

However, the dilution calculated using Equation (3) displays an obvious higher value than that using the other two ways for heat inputs at any level either for the gross weld dilution $D_{w A l l}$ or for the Si dilution $D_{w s i}$. This dilution value derived from the new formula agrees well with the essential meaning of dilution in welding. For example, the filler wire used in our study is rich in Si composition, which is $11.06 \mathrm{wt} \%$, far more than that of $0.66 \mathrm{wt} \%$ in the substrate. Hence, after welding, it is evident that the Si concentrations in all weld beads are going to be higher than that in the substrate. For the $0.12 \mathrm{~kJ} / \mathrm{mm}$ bead, the concentration of composition Si is $5.87 \mathrm{wt} \%$, which is far beyond $0.66 \mathrm{wt} \%$ in substrate. That is to say, after welding the element $\mathrm{Si}$ is concentrated but not diluted. However, the dilution obtained from Equations (1) and (2) is only $49.87 \%$ and $25.30 \%$, respectively, which means that the element concentration decreases compared with the original substrate composition. While the truth is that it sharply increases almost 9 times, the dilution from either Equation (1) or Equation (2) is obviously contradictive with the chemical analysis by EDS. However, this phenomenon can be perfectly indicated by the dilution result from Equation (3) with its value soaring to $885.43 \%$. Moreover, different compositions have their own concentrations, thus have separate dilution; yet Equation (2), the geometric calculation method, can produce only one value in total for every individual composition in a weld. It is hard for researchers to decide which composition dilution it reveals exactly. Therefore, Equation (3), instead of Equations (1) and (2), is a more rational method to calculate composition dilution.

The dilution result is affected by several factors, the possible sources of error are the non-uniform distribution of composition and the effect of processing parameters. Take the distribution of $\mathrm{Si}$ composition as an example, the Si dilution value is high where the concentration of $\mathrm{Si}$ in filler wire or base metal is higher according to Equation (3). Besides, the dilution is also determined by the unstable processing parameters. The Si dilution value is high when the traveling speed is at a low level, for which there are more molten filler wire deposited into the weld, whose concentration of $\mathrm{Si}$ is higher than the base metal.Different current levels result in different bead profiles. Figure 5 displays the corresponding profiles of each heat input. From the profiles, we can find that the height of the front reinforcement decreases and the height of the back reinforcement increases with the heat input increasing.
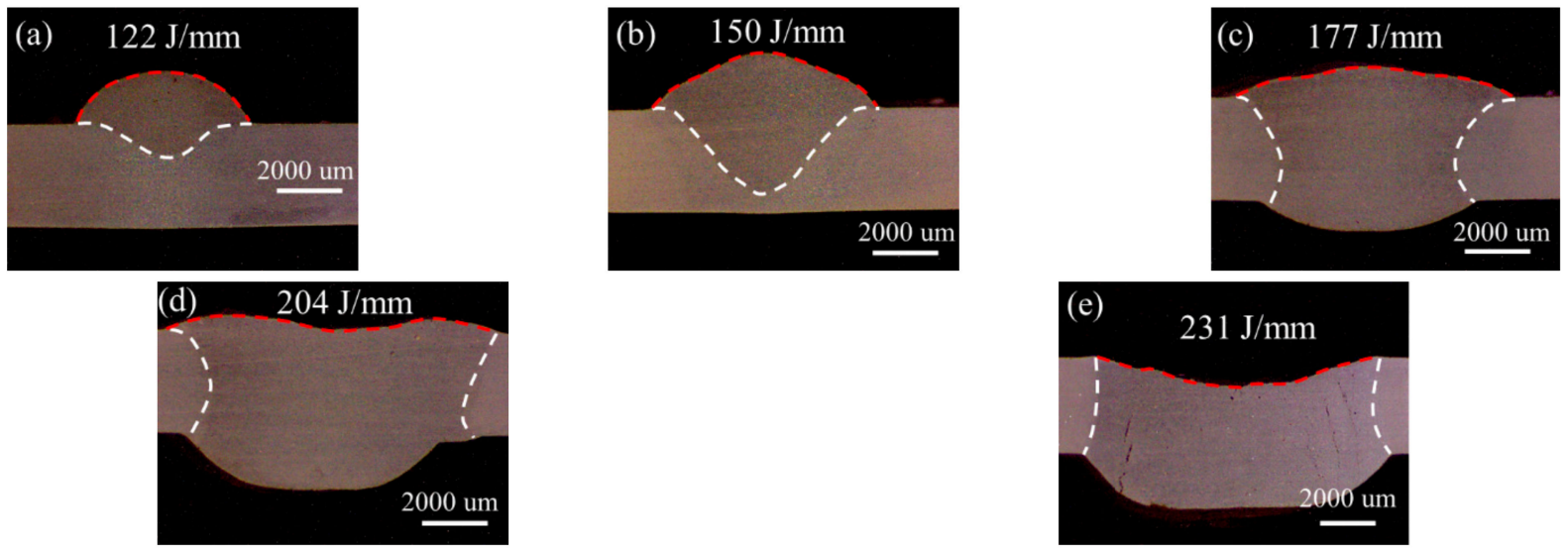

Figure 5. Corresponding bead profile for each heat input: (a) $0.12 \mathrm{~kJ} / \mathrm{mm}$; (b) $0.15 \mathrm{~kJ} / \mathrm{mm}$; (c) $0.18 \mathrm{~kJ} / \mathrm{mm}$; (d) $0.20 \mathrm{~kJ} / \mathrm{mm}$; (e) $0.23 \mathrm{~kJ} / \mathrm{mm}$. 
In addition, to evaluate the gross dilution for welds consisting of more than one major alloying composition, the proposed method can be modified as Equation (4) to integrate all the targeted major compositions by introducing a weight coefficient. In Equation (4), the subscript $A, X, \ldots, N$ are represented as the major compositions, and $C_{w X}$ and $C_{S X}$ are the concentrations of a certain composition in bead and substrate, respectively. Therefore, $C_{w X} / C_{s X}$ is the dilution for a certain element, while $\frac{C_{S X}}{C_{S A}+C_{S X}+\cdots+C_{S N}}$ is the weight coefficient of the corresponding element, and the product of them is the dilution share that a certain element occupies. Adding all these individual dilution products up, we will get the gross weld dilution ratio formula Equation (4), which can be further simplified as Equation (5). In our study, for the major compositions of $\mathrm{Mg}$ and $\mathrm{Si}$, the gross weld dilution $D_{w A l l}$ can be expressed simply as Equation (6) according to Equation (5), where $C_{w M g}$ and $C_{w S i}$ are the concentrations of $\mathrm{Mg}$ and $\mathrm{Si}$ in bead after welding, while $C_{s M g}$ and $\mathrm{C}_{S S i}$ the concentrations of $\mathrm{Mg}$ and $\mathrm{Si}$ in substrate before welding. In fact, Equation (3) is also a simplified form of Equation (5) but for the bead consisting of only one major alloying composition. From this aspect, Equation (5) exhibits great superiority over the existing two methods for its widespread application to various welds alloying either one or more compositions. The gross weld dilution calculated using Equations (5) and (2) is represented in Figure 4 and Table 4, from which Equation (5) results in a higher dilution value than that using Equation (2) even if Equation (2) can be regarded as a way to calculate the gross dilution. The higher dilution from Equation (5) is attributed to the addition of Si-enriched filler wire in which the Si concentration is about 16.76 times of that in the substrate. Hence, although the $\mathrm{Mg}$ dilution is at a lower value of $27.48 \%$ using Equation (3) for $0.12 \mathrm{~kJ} / \mathrm{mm}$ bead, the significant excess of $\mathrm{Si}$ in filler wire than that in substrate still has the ability to not only compensate for the decrease in $\mathrm{Mg}$ dilution but also to elevate the whole weld dilution up to as high as $594.08 \%$. Namely, the gross dilution value $D_{w A l l}$ is much closer to the individual dilution value, which has a higher weight coefficient. The geometric calculation method using Equation (2); however, has no ability to reveal the complicated effect of how individual dilution affects the gross dilution for a multiple compositions bead.

$$
\begin{gathered}
D_{w}(\%)=\sum_{A}^{N}\left(\frac{C_{w X}}{C_{s X}} \times \frac{C_{s X}}{C_{s A}+C_{s X}+\cdots+C_{s N}}\right) \\
D_{w}(\%)=\frac{C_{w A}+C_{w X}+\cdots+C_{w N}}{C_{s A}+C_{s X}+\cdots+C_{s N}} \\
D_{w A l l}(\%)=\frac{C_{w M g}+C_{w S i}}{C_{s M g}+C_{s S i}}
\end{gathered}
$$

\subsection{Effect of Heat Input on Dilution}

Figure 4 and Table 4 demonstrates the effect of heat input on dilution as well. As the dashed lines show, the dilution values calculated using Equations (1) and (2) for all levels of heat inputs are restricted in a narrow range of $0 \sim 1$, which is consistent with the conclusion deduced from the mathematical formula. All the dashed lines show a similar tendency that the dilution increases sharply with the heat input when the current is at a low level. However, all the dilutions remain stable after the heat input reaches $0.18 \mathrm{~kJ} / \mathrm{mm}$. The geometric method Equation (2) yields the dilutions $\mathrm{D}_{\mathrm{Geo}}$ which are between the compositions of $\mathrm{Si}$ and $\mathrm{Mg}$ across much of the investigated range. The $\mathrm{Mg}$ dilution $\mathrm{D}_{\mathrm{wMg}}$ using our method is always slightly higher than that from Equation (1), which is attributed to the trace amount of composition $\mathrm{Mg}$ in filler wire. According to Equation (1), if the concentration of composition in filler wire comes to zero, then Equation (1) becomes no different from Equation (3). The lesser a composition is in filler wire, the closer the corresponding dilutions are after welding because under these conditions, the concentrations are mainly determined by the original substrate due to the weak involvement of filler wire. 
The solid lines of Si dilution $\mathrm{D}_{\mathrm{wSi}}$ and the gross weld dilution $\mathrm{D}_{\mathrm{wAll}}$ using Equation (5) display a quite different result from the other ways. Unlike the $\mathrm{Mg}$ dilution $\mathrm{D}_{\mathrm{wMg}}$ which increases with heat input, both Si dilution and the gross weld dilution decreases with heat input at first and then is stable with slight fluctuation after $0.18 \mathrm{~kJ} / \mathrm{mm}$, which can be regard as the transition point (TP) for both dilutions and the profiles of beads. Before TP, the substrate is partially penetrated and dilutions change violently with the increase of heat input. However, once heat input is higher than TP, the substrate is fully penetrated and dilutions changes in a fairly narrow range. This is also true for Equation (2), although the specific values are different because its dilutions derive from the chemical composition analysis as Equation (5) does. In fact, for a certain composition, as long as the absolute difference value in concentration between a bead and the original substrate increases, the weld becomes either more diluted or more concentrated. In mathematics, the dilution value for the former becomes increasingly less than 1 , and the latter increasingly greater than 1 , as represented by the arrows in Figure 4. This means that critical value 1 is the transformation point. When the dilution is greater than 1 , the weld is concentrated, otherwise, the weld is diluted. When the dilution equals to 1 , the line of the original compositions, it means that the composition $C_{w X}$ after welding equals to $C_{s X}$ before welding. Nevertheless, Figure 4 and Table 4 display that although a certain composition is diluted (such as $\mathrm{Mg}$ ) or concentrated (for example $\mathrm{Si}$ ) at a level of heat input, the compositions' concentration always approaches to that of the original substrate as long as the heat input increases. This is attributed to the intenser convection in a weld pool from a higher heat input than that from a lower heat input [19]. The convection in the weld pool is determined by many factors including droplet impingement, heat input [25], etc. The higher the heat input is, the intenser the convection is, which produces a more uniform mixture between the filler wire and the base metal. Thus, the compositions of beads come to that of the original substrate with the increase of heat input, and in Figure 4 this phenomenon is displayed as the values higher or lower than 1 approaching to the critical value line. Moreover, the butt weld with the same parameters of $0.18 \mathrm{~kJ} / \mathrm{mm}$ as bead on plate weld is investigated as well; it, however, shows no evident difference in dilution value. This indicates when there is no gap between base metal parts, the bead on plate weld and the butt weld has the same dilution value.

\section{Conclusions}

In this paper, a new method for weld dilution calculation was proposed and the effect of heat inputs on the dilution was discussed. The main conclusions are as follows:

(1) Compared with the existing method, the proposed method in our paper agrees better with the definition of dilution in welding, which has a widespread application to welds alloying either one or more compositions. For the beads alloying two or more compositions, the dilution values vary widely according to the relative composition concentration between the filler metal and the substrate.

(2) The new method removes the mathematical restriction of forcing the dilution variation into a limited range of $0 \sim 1$ by the existing methods, by which it reveals more clearly the phenomenon that when a bead dilution is greater than the critical value 1 , the composition is concentrated, such as the Si dilution soaring to $885.43 \%$ from $49.87 \%$ (chemical method) and $25.30 \%$ (geometric method), while when the value falls into $0 \sim 1$, the bead is diluted. However, the gross weld dilution value $D_{w A l l}$ is much closer to the individual dilution value which has a higher weight coefficient.

(3) Whether a certain composition is diluted or concentrated under a low level of heat input, the increase of the heat input propels the compositions' concentration toward that of the original substrate. However, the dilution becomes stable once the heat input is beyond the transition point $0.18 \mathrm{~kJ} / \mathrm{mm}$ in our case, which may result from the adequate convection of molten pool caused by the high-level heat input. 
Author Contributions: Conceptualization, Z.Z. and X.H.; methodology, P.Y.; resources, J.X.; writingoriginal draft preparation, Z.Z.; writing—review and editing, P.Y.; supervision, X.H.; project administration, J.X. All authors have read and agreed to the published version of the manuscript.

Funding: This research was funded by Guangdong Basic and Applied Basic Research Foundation, (2019A1515110627), National Natural Science Foundation of China, (51805099, 51875213), Project of Educational Commission of Guangdong Province of China (2020ZDZX2019), 2018 Joint Graduate Training Foundation Project, Science and Technology Program of Guangzhou, China (201805010001).

Institutional Review Board Statement: Not applicable.

Informed Consent Statement: Not applicable.

Data Availability Statement: Not applicable.

Conflicts of Interest: The authors declare no conflict of interest.

\section{References}

1. Marashi, P.; Pouranvari, M.; Amirabdollahian, S.; Abedi, A.; Goodarzi, M. Microstructure and failure behavior of dissimilar resistance spot welds between low carbon galvanized and austenitic stainless steels. Mater. Sci. Eng. A 2008, 480, 175-180. [CrossRef]

2. Sierra, G.; Peyre, P.; Deschaux-Beaume, F.; Stuart, D.; Fras, G. Steel to aluminium key-Hole laser welding. Mater. Sci. Eng. A 2007, 447, 197-208. [CrossRef]

3. Yao, C.; Xu, B.; Zhang, X.; Huang, J.; Fu, J.; Wu, Y. Interface microstructure and mechanical properties of laser welding copper-steel dissimilar joint. Opt. Lasers Eng. 2009, 47, 807-814. [CrossRef]

4. Ranjbarnodeh, E.; Serajzadeh, S.; Kokabi, A.H.; Fischer, A. Effect of welding parameters on residual stresses in dissimilar joint of stainless steel to carbon steel. J. Mater. Sci. 2011, 46, 3225-3232. [CrossRef]

5. Hou, J.; Peng, Q.J.; Takeda, Y.; Kuniya, J.; Shoji, T.; Wang, J.Q.; Han, E.H.; Ke, W. Microstructure and mechanical property of the fusion boundary region in an alloy 182-low alloy steel dissimilar weld joint. J. Mater. Sci. 2010, 45, 5332-5338. [CrossRef]

6. Svensson, L.E. Prediction of hardness of spot welds in steels. Weld. World 2004, 48, 31-35. [CrossRef]

7. Hernandez, B.V.H.; Kuntz, M.L.; Khan, M.I.; Zhou, Y. Influence of microstructure and weld size on the mechanical behaviour of dissimilar AHSS resistance spot welds. Sci. Technol. Weld. Join. 2008, 13, 769-776. [CrossRef]

8. Ramjaun, T.I.; Stone, H.J.; Karlsson, L.; Kelleher, J.; Ooi, S.W.; Dalaei, K.; Kornmeier, J.R.; Bhadeshia, H.K.D.H. Effects of dilution and baseplate strength on stress distributions in multipass welds deposited using low transformation temperature filler alloys. Sci. Technol. Weld. Join. 2014, 19, 461-467. [CrossRef]

9. Sun, Y.L.; Hamelin, C.J.; Vasileiou, A.N.; Xiong, Q.; Flint, T.F.; Obasi, G.; Francis, J.A.; Smith, M.C. Effects of dilution on the hardness and residual stresses in multipass steel weldments. Int. J. Press. Vessel. Pip. 2020, 187, 104154. [CrossRef]

10. Zhang, M.L.Y.; Chen, S.; Rong, L.; Lu, H. Effect of dilution ratio of the first 3091 cladding layer on the microstructure and mechanical properties of weld joint of connecting pipe-Nozzle to safe-End in nuclear power plant. Acta Metall. Sin. 2020, 56, 1057-1066.

11. Gualco, A.; Svoboda, H.N.G.; Surian, E.S. Effect of heat input on the Fe-Based nanostructured weld overlay. Weld. Int. 2015, 29, 847-855. [CrossRef]

12. Banovic, S.W.; DuPont, I.N.; Marder, A.R. Dilution control in gas-Tungsten-Arc welds involving superaustenitic stainless steels and nickel-Based alloys. Metall. Mater. Trans. B 2001, 32, 1171-1176. [CrossRef]

13. Silva, C.C.; Afonso, C.R.M.; Ramirez, A.J.; Motta, M.F.; Miranda, H.C.; Farias, J.P. Assessment of microstructure of alloy Inconel 686 dissimilar weld claddings. J. Alloys Compd. 2016, 684, 628-642. [CrossRef]

14. Sayyar, N.; Shamanian, M.; Niroumand, B. Arc weldability of Incoloy 825 to AISI 321 stainless steel welds. J. Mate. Process. Technol. 2018, 262, 562-570. [CrossRef]

15. Yuan, T.; Chai, X.; Luo, Z.; Kou, S. Predicting susceptibility of magnesium alloys to weld-edge cracking. Acta Mater. 2015, 90, 242-251. [CrossRef]

16. Pickin, C.G.; Williams, S.W.; Lunt, M. Characterisation of the cold metal transfer (CMT) process and its application for low dilution cladding. J. Mater. Process. Technol. 2011, 211, 496-502. [CrossRef]

17. Liang, Y.; Hu, S.; Shen, J.; Zhang, H.; Wang, P. Geometrical and microstructural characteristics of the TIG-CMT hybrid welding in 6061 aluminum alloy cladding. J. Mater. Process. Technol. 2017, 239, 18-30. [CrossRef]

18. Sharma, A.; Arora, N.; Mishra, B.K. Mathematical model of bead profile in high deposition welds. J. Mater. Process. Technol. 2015, 220, 65-75. [CrossRef]

19. Hejripour, F.; Valentine, D.T.; Aidun, D.K. Study of mass transport in cold wire deposition for wire arc additive manufacturing. Int. J. Heat Mass Transf. 2018, 125, 471-484. [CrossRef]

20. Zhu, Q.; Xue, J.; Yao, P.; Dong, C.; Wang, L.; Heng, G.; Li, Z. Gaussian pulsed current waveform welding for aluminum alloys. Mater. Manuf. Process. 2014, 30, 1124-1130. [CrossRef] 
21. Wang, L.; Jin, L.; Huang, W.; Xu, M.; Xue, J. Effect of thermal frequency on AA6061 aluminum alloy double pulsed gas metal arc welding. Mater. Manuf. Process. 2015, 31, 2152-2157. [CrossRef]

22. Feng, Y.; Luo, Z.; Liu, Z.; Li, Y.; Luo, Y.; Huang, Y. Keyhole gas tungsten arc welding of AISI 3161 stainless steel. Mater. Des. 2015, 85, 24-31. [CrossRef]

23. Pang, J.; Hu, S.; Shen, J.; Wang, P.; Liang, Y. Arc characteristics and metal transfer behavior of CMT + p welding process. J. Mater. Process. Technol. 2016, 238, 212-217. [CrossRef]

24. Zhang, Z.; Xue, J. Profile map of weld beads and its formation mechanism in gas metal arc welding. Metals 2019, 9, 146. [CrossRef]

25. Zhang, Z.; Xue, J.; Jin, L.; Wu, W. Effect of droplet impingement on the weld profile and grain morphology in the welding of aluminum alloys. Appl. Sci. 2018, 8, 1203. [CrossRef] 